\title{
ESTAFILOCOCOS COAGULASE POSITIVA EM QUEIJOS MINAS FRESCAL E MINAS PADRÃO COMERCIALIZADOS EM PELOTAS, RIO GRANDE DO SUL
}

\author{
FERNANDO ZOCCHE * \\ CAROLINE PEIXOTO BASTOS** \\ MILENA TOMASI BASSANI *** \\ RODRIGO CORREA FRANÇA**** \\ ANDRÉIA SALDANHA DE LIMA***** \\ WLADIMIR PADILHA DA SILVA
}

\begin{abstract}
O objetivo deste estudo foi avaliar a presença de Estafilococos coagulase positiva (ECP) em amostras de queijos industrializados Minas Frescal e Minas Padrão, comercializados na cidade de Pelotas, Rio Grande do Sul. Foram avaliadas vinte e oito (28) amostras de queijo minas frescal e quarenta e quatro (44) de queijo minas padrão, coletadas no comércio local. Quatro amostras apresentaram contaminação acima do padrão estabelecido pela RDC 12, de 12 de janeiro de 2001 (ANVISA), sendo três de queijo minas frescal e uma de queijo minas padrão. A presença de ECP é preocupante uma vez que esses micro-organismos podem se multiplicar, produzir e secretar toxinas em níveis suficientes para causar intoxicação alimentar estafilocócica, enfermidade transmitida por alimentos de grande importância em saúde pública.
\end{abstract}

PAVAVRAS-CHAVE: CONTAMINAÇÃO; QUEIJO; ETA; ECP; Staphylococcus.

* Médico Veterinário, Professor, Doutor em Ciências, Universidade Federal do Pampa, Dom Pedrito, RS, Brasil (e-mail: fernandozocche@unipampa.edu.br).

* Química de Alimentos, M.Sc. em Ciências, Doutoranda do Programa de Pós Graduação em Ciência e Tecnologia Agroindustrial, Laboratório de Microbiologia de Alimentos, Departamento de Ciência e Tecnologia Agroindustrial (DCTA), Faculdade de Agronomia Eliseu Maciel (FAEM), Universidade Federal de Pelotas (UFPel), Pelotas RS, Brasil (e-mail: carolpebastos@yahoo.com.br).

*** Médica Veterinária, M.Sc. em Ciências, Doutoranda do Programa de Pós Graduação em Ciência e Tecnologia Agroindustrial, Laboratório de Microbiologia de Alimentos, DCTA, FAEM, UFPel, Pelotas, RS, Brasil (e-mail: mtbassani@yahoo.com.br).

**** Médico Veterinário, M. Sc. em Ciências, Doutorando em Biotecnologia, Laboratório de Microbiologia de Alimentos, DCTA, FAEM, UFPel, Bolsista FAPERGS, Pelotas, RS, Brasil (e-mail: rodrigodfranca@yahoo. com.br).

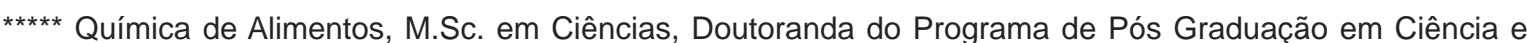
Tecnologia Agroindustrial, Laboratório de Microbiologia de Alimentos, DCTA, FAEM, UFPel, Pelotas, RS, Brasil (e-mail: saldanha_andreia@hotmail.com).

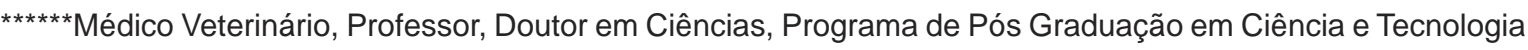
Agroindustrial, Laboratório de Microbiologia de Alimentos, DCTA, FAEM, UFPel, Pelotas, RS, Brasil (e-mail: silvawp@ufpel.edu.br). 


\section{INTRODUÇÃo}

A produção de queijos constitui uma das mais importantes atividades das indústrias de laticínios, sobretudo no Brasil (LISITA, 2005). O queijo caracteriza-se por ser alimento preparado com leite acrescido de materiais biológicos (coalho e micro-organismos) e outros ingredientes (PERRY, 2004). No entanto, embora o processo básico de fabricação de queijos seja comum a quase todas as variedades, diferenças na origem do leite, nas técnicas de processamento e no tempo de maturação criam a imensa variedade conhecida (PERRY, 2004). O consumo de queijos no Brasil é de 3,1Kg/pessoa/ano, mostrando-se bastante reduzido quando comparado ao da Argentina (11,2 Kg/pessoa/ano), Estados Unidos da América (14,9 Kg/pessoa/ano) ou de países europeus (13 Kg/pessoa/ano) (EMBRAPA, 2008). Aproximadamente $25 \%$ do leite produzido no Brasil é destinado à produção de queijos, principalmente dos tipos mussarela e minas frescal, os quais são incluídos entre os queijos de maior aceitação por parte dos consumidores brasileiros (FERNANDES, ANDREATTA e OLIVEIRA, 2006). Durante a produção dos queijos, diversos fatores podem alterar suas características, dentre as quais se destacam: tipo de coagulação (ácida ou enzimática), más práticas de fabricação, contaminação do leite após o processamento térmico, temperatura inadequada de armazenamento e matéria-prima com alta carga microbiana inicial, além do processo de fabricação. Para fabricação de queijo minas frescal, embora seja utilizada com frequência a coagulação enzimática, essa coagulação pode ser associada com a utilização de bactérias lácticas, cuja presença pode interferir impedindo e/ou reduzindo a multiplicação de microorganismos contaminantes. A contaminação microbiológica representa sério perigo para a saúde do consumidor, especialmente dos grupos de risco (como crianças e idosos), além de causar grandes prejuízos econômicos aos laticínios pela degradação da matéria-prima utilizada (PERRY, 2004).

Entre os micro-organismos que podem contaminar o queijo destacam-se os do gênero Staphylococcus, em especial os que produzem coagulase, enzima que está intimamente ligada à produção de termonuclease. Por muitos anos $S$. aureus foi considerada a única espécie do gênero Staphylococcus capaz de produzir coagulase e potencialmente produtora de enterotoxinas. Posteriormente, outras espécies produtoras de enterotoxinas e de coagulase, tais como $\mathrm{S}$. hyicus e S. intermedius, foram identificadas e, inclusive, surtos de intoxicação alimentar já foram atribuídos a essas duas espécies (SILVA e GANDRA, 2004). A presença de estafilococos coagulase positiva acima dos índices máximos permitidos pela legislação (BRASIL, 2001), além de evidenciar a ineficiência ou ausência de controle da matéria-prima, do processo de fabricação ou do produto acabado, indica a possibilidade da veiculação de outros patógenos responsáveis pela ocorrência de enfermidades transmitidas pelos alimentos (ETA).

O objetivo deste estudo foi avaliar a presença de Estafilococos coagulase positiva em amostras de queijo minas frescal e queijo minas padrão, comercializados na cidade de Pelotas, Rio Grande do Sul.

\section{MATERIAL E MÉTODOS}

Foram avaliadas 28 amostras de queijo minas frescal e 44 de queijo minas padrão, fabricados industrialmente. As amostras foram coletadas no comércio da cidade de Pelotas (RS), armazenadas em caixa isotérmica contendo gelo e enviadas ao Laboratório de Microbiologia de Alimentos do Departamento de Ciência e Tecnologia Agroindustrial, Faculdade de Agronomia Eliseu Maciel, Universidade Federal de Pelotas, sendo mantidas em temperatura de refrigeração até o início das análises. Vinte e cinco gramas de queijo minas frescal ou minas padrão foram individualmente adicionadas a $225 \mathrm{~mL}$ de solução salina $0,85 \%(\mathrm{p} / \mathrm{v})$, compondo a diluição $10^{-1}$ desse alimento. A partir dessa, procederam-se diluições decimais seriadas em solução salina até se obter a diluição $10^{-3}$. Alíquotas de $0,1 \mathrm{~mL}$ de cada uma das diluições foram semeadas na superfície de placas contendo ágar Baird-Parker suplementado com 5\% de gema de ovo e $1 \%$ de telurito de 
potássio, e espalhadas com auxílio de bastão de Drigalsky, sendo posteriormente incubadas a $37^{\circ} \mathrm{C}$ durante 48 horas. Colônias apresentando dois halos (opaco e de transparência) foram consideradas típicas e repicadas para $4 \mathrm{~mL}$ de caldo infusão de cérebro e coração $(\mathrm{BHI})$ com posterior incubação a $37^{\circ} \mathrm{C}$ durante 24 horas. Após, $0,3 \mathrm{~mL}$ desse inóculo foi repassado para microtubos contendo $0,3 \mathrm{~mL}$ de plasma de coelho, que foram incubados a $37^{\circ} \mathrm{C}$, avaliando-se a produção de coagulase livre a cada 1 hora, durante período de $6 \mathrm{~h}$. Foram consideradas positivas apenas as culturas que apresentaram coágulo de 3 e 4 cruzes conforme descrito por Lancette e Bennet (2001).

\section{RESULTADOS E DISCUSSÃO}

Os resultados obtidos na pesquisa de estafilococos coagulase positiva (ECP) em amostras de queijo minas frescal e minas padrão comercializados em Pelotas (RS) podem ser visualizados na Figura 1.
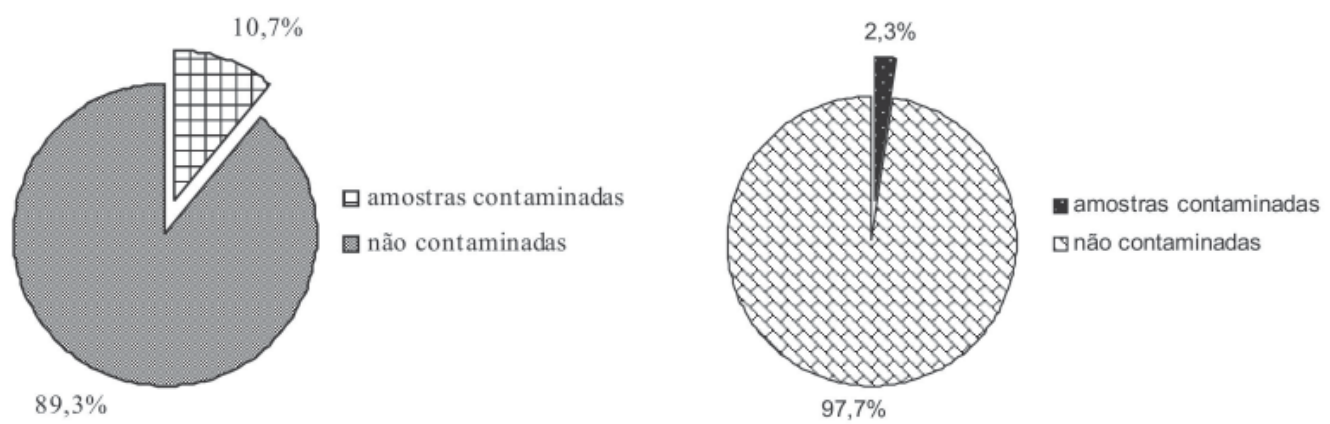
FIGURA 1 - PERCENTUAL DE AMOSTRAS DE QUEIJO MINAS FRESCAL (A) E QUEIJO MINAS PADRÃO (B) CONTAMINADAS POR ESTAFILOCOCOS COAGULASE POSITIVA E EM DESACORDO COM O ESTABELECIDO PELA RDC 12 (BRASIL, 2001)

Isolou-se ECP em 3 das 28 amostras de queijo minas frescal e em 4 das 44 amostras de queijo minas padrão. Entretanto, as 3 amostras de queijo minas frescal apresentaram contagens superiores ao estipulado pela RDC 12 (BRASIL, 2001), verificando-se apenas 1 amostra de queijo minas padrão nessa condição (Tabela 1).

TABELA 1 - CONCENTRAÇÃO DE ESTAFILOCOCOS COAGULASE POSITIVA EM AMOSTRAS DE QUEIJO MINAS FRESCAL E MINAS PADRÃO INDUSTRIALIZADOS E COMERCIALIZADOS NA CIDADE DE PELOTAS (RS) E LIMITES ESTIPULADOS PELA RDC 12 PARA ESSES ALIMENTOS

\begin{tabular}{c|c|c}
\hline Queijo minas & Concentração bacteriana (UFC.g $\left.{ }^{-1}\right)$ & Limite padrão para amostra indicativa \\
\hline Frescal & $2 \times 10^{3}$ & \\
Frescal & $4,1 \times 10^{5}$ & $5 \times 10^{2} \mathrm{UFC} . g^{-1}$ \\
Frescal & $10^{3}$ & \\
Padrão & $9,8 \times 10^{2}$ & \\
Padrão & $7,5 \times 10^{2}$ & $10^{3} \mathrm{UFC} . g^{-1}$ \\
Padrão & $1,3 \times 10^{5}$ & \\
Padrão & $2,0 \times 10^{2}$ & \\
\hline
\end{tabular}

* RDC 12 (BRASIL, 2001). 
A concentração bacteriana requerida pelas cepas toxigênicas de ECP para a produção de enterotoxinas em quantidade suficiente para a ocorrência de intoxicação alimentar estafilocócica é de, no mínimo, $10^{5}$ UFC.g ${ }^{-1}$ (LANCETTE E BENNET, 2001). Uma amostra (2,3\%) de queijo minas padrão e 1 amostra (3,6\%) de queijo minas frescal apresentaram concentração bacteriana superior a esse valor (Tabela 1 ) e podem ser consideradas como potencialmente capazes de causar intoxicação alimentar em humanos, caso as cepas sejam produtoras de toxinas.

Índices superiores aos encontrados neste estudo foram relatados por Almeida Filho e Nader Filho (2000), Loguercio e Aleixo (2001) e por Almeida et al. (2006), os quais encontraram 50\%, $43,3 \%$ e $67 \%$ respectivamente, de amostras de queijo minas frescal com índices de contaminação potencialmente capazes de causar intoxicação alimentar. Além disso, Loguercio e Aleixo (2001) constataram que $96,67 \%$ das amostras de queijo minas frescal estavam em desacordo com o padrão legal vigente.

Vale ressaltar que 65 amostras não apresentaram contaminação por ECP. Esse resultado indica que o processamento térmico da matéria-prima foi adequado, aliado a boas práticas de fabricação, que impediram a recontaminação do produto final. Além disso, pode ser reflexo da boa qualidade da matéria-prima utilizada e/ou ação intensa de microbiota competidora (bactérias láticas). Valores bastante superiores foram relatados por Salotti et al. (2006), que encontraram 66,7\% das amostras de queijo minas frescal industrializado com índices de ECP acima do estabelecido pela RDC 12 (BRASIL, 2001).

Loguercio e Aleixo (2001), Salotti et al. (2006) e Borelli et al. (2006) observaram nível de contaminação ainda maior quando os queijos foram fabricados por processos artesanais. Tais autores atribuíram a contaminação, em parte, à alta carga microbiana da matéria-prima, à microbiota potencialmente patogênica presente no ambiente e utensílios de fabricação, bem como à incorporação de bactérias devido à incorreta manipulação e armazenamento do produto. É possível descrever faixa bastante ampla de contaminação em queijo minas frescal por ECP em distintos estudos realizados no Brasil, variando de 0\% (GRANDI e ROSSI, 2007) a 100\% (HOFFMANN, SILVA e VINTUTIM, 2002) de amostras contaminadas. Komatsu et al. (2010) analisaram queijos minas frescal em Uberlância (MG), encontrando 88\% das amostras em desacordo com a RDC 12 (BRASIL, 2001) e atribuíram a alta taxa de contaminação à ausência de controle higiênico sanitário na fabricação desse alimento.

Com relação ao queijo minas padrão, valores semelhantes aos obtidos neste estudo foram verificados por Melo, Alves e Costa (2009), que analisaram o mesmo tipo de queijo na cidade de São Luis (MA) e encontraram 6,6,\% das amostras excedendo o valor estipulado pela legislação. Por outro lado, Almeida e Silva (2010), ao avaliarem aspectos microbiológicos e físico-químicos em distintos produtos lácteos em Muriaé (MG) constataram resultados satisfatórios em apenas 8,3\% das amostras de queijo minas padrão.

Comparando-se a contaminação por ECP entre os dois distintos tipos de queijo, observase menor quantidade de amostras de queijo minas padrão com contaminação além do tolerado (BRASIL, 2001), o que pode ser atribuído às características de fabricação, particularmente ao tempo de cura do alimento que reduz sua umidade e que poderia contribuir para diminuir as contagens desses micro-organismos. Arruda et al. (2007), analisando os mesmos tipos de queijos em Goiás (GO), encontraram 100\% das amostras de queijo minas frescal e $75 \%$ das amostras de queijo minas padrão inadequadas para o consumo, devido à contagens de ECP além do parâmetro máximo permitido pela RDC 12 (BRASIL, 2001).

A presença de ECP nos dois tipos de queijos demonstra o risco de intoxicação alimentar estafilocócica associado a esses produtos, mesmo naqueles cuja contagem ficou abaixo do estabelecido pela legislação, pois se forem armazenados em condições de abuso de temperatura podem favorecer o desenvolvimento bacteriano com consequente produção de toxinas até níveis capazes de causar doença. 


\section{CONCLUSÃO}

A presença de ECP nos queijos minas frescal e minas padrão analisados é preocupante uma vez que os micro-organismos podem se multiplicar, produzir toxina e causar intoxicação.

Tratando-se de queijos industrialmente fabricados, supõe-se que ECP tenham sido incorporados aos queijos por contaminação cruzada mediante equipamentos, utensílios e/ou manipuladores de alimentos.

\section{ABSTRACT \\ Coagulase positive Staphylococcus IN MINAS FRESCAL AND MINAS PADRÃO CHEESE COMMERCIALIZED IN PELOTAS, RIO GRANDE DO SUL (BRAZIL)}

The aim of this study was to evaluate the presence of coagulase positive Staphylococci (CPS) in industrialized Minas Frescal and Minas Padrão cheese samples, commercialized in the city of Pelotas, Rio Grande do Sul (BRAZIL). Twenty-eight (28) samples of Minas Frescal cheese and forty-four (44) samples of Minas Padrão cheese collected from local traders were evaluated. Four samples presented contamination levels above the standard set by the RDC12, on 12 January 2001 (Ministry of Health), three of Minas Frescal cheese and one of Minas Padrão cheese. The presence of CPS is worrying since these microorganisms can multiply, produce and secret toxins at levels sufficient to cause staphylococcal food poisoning, an illness transmitted by food of great importance in public health.

KEY-WORDS: FOOD; CONTAMINATION; Staphylococcus; CHEESE; ETA; SCP.

\section{REFERÊNCIAS}

1 ALMEIDA, A.D.; MENDES, A.; PEREIRA, F.F.; PASQUA, M.C.; VEIGA, S.M.O.M. Pesquisa de Staphylococcus coagulase positivo em queijo minas frescal comercializado na cidade de Alfenas, MG. Higiene Alimentar, São Paulo, v.20, n. 147, p. 45-50, 2006

2 ALMEIDA FILHO, E.S.; NADER FILHO, A. Ocorrência de Staphylococcus aureus em queijo tipo "frescal". Revista de Saúde Pública, São Paulo, v.34, n.6, p.578-580, 2000.

3 ALMEIDA, J. A.; SILVA, M.F. Avaliação da qualidade microbiológica e físico-química dos produtos lácteos inspecionados pelo Serviço de Inspeção Municipal de Muriaé - MG. In: CONGRESSO NACIONAL DE LATICíNIOS, 27., Juiz de Fora, 2010. Anais... Juiz de Fora: Instituto de Laticínios Candido Tostes, 2010.

4 ARRUDA, M. L. T.; NICOLAU, E. S.; REIS, A. P.; ARAÚJO, A. S.; MESQUITA, A. J. Ocorrência de Staphylococcus coagulase positiva em queijos Minas tipos frescal e padrão comercializados nas feiras-livres de Goiânia-GO. Revista do Instituto Adolfo Lutz, São Paulo, v. 66, n.3, p. 292-298, 2007.

5 BORELLI, B.M.; FERREIRA, E.G.; LACERDA, I.C.A.; SANTOS, D.A.; CARMO, L.S.; DIAS, R.S.; SILVA, M.C.C.; ROSA, C.A. Enterotoxigenic Staphylococcus spp. and other microbial contaminants during production of canastra cheese, Brazil. Brazilian Journal of Microbiology, São Paulo, v. 37, p. 545-550, 2006.

6 BRASIL. Agência Nacional de Vigilância Sanitária. RDC n 12, de 02 de Janeiro de 2001. Regulamento técnico sobre padrões microbiológicos para alimentos. Diário Oficial [da] República Federativa do Brasil, Brasília, n. 7-E, p. 46-53, 10 Jan. 2001, seção l.

7 Empresa Brasileira de Pesquisa Agropecuária (EMBRAPA). Consumo per capita anual de queijos - 2000/2008. Disponível em: http://www.cnpgl.embrapa.br/nova/informacoes/estatisticas/consumo/tabela0705.php. Juiz de Fora. Acesso em: 24/05/2012

8 FERNANDES, A.M.; ANDREATTA, E.; OLIVEIRA, C.A.F. Ocorrência de bactérias patogênicas em queijos no Brasil: questão de saúde pública. Higiene Alimentar, São Paulo, v.20, n. 144, p. 49-56, 2006.

9 GRANDI, A. Z.; ROSSI, D.A. Qualidade microbiológica do queijo minas frescal comercializado na cidade de UberlândiaMG. Horizonte Científico, Uberlândia, v. 1, n1, p.1-18, 2007. Disponível em: http://www.seer.ufu.br/index.php/ horizontecientifico/issue/view/308 Acesso em: 24/05/2012.

10 HOFFMANN, F. L.; SILVA, J. V. da; VINTURIM, T. M. Qualidade microbiológica de queijos "Minas Frescal", vendidos em feiras livres na região de São José do Rio Preto, SP. Revista Higiene Alimentar, São Paulo, v. 16, n. 96, p. 69-76, 2002. 
11 KOMATSU, R.S.; RODRIGUES, M.A.M.; LORENO, W.B.N.; SANTOS, K.A. Ocorrência de Staphylococcus coagulase positiva em queijos minas frescal produzidos em Uberlândia-MG. Bioscience Journal, Uberlândia, v. 26, n. 2, p. 316321, 2010.

12 LANCETTE, G.A.; BENNETT, R.W. Staphylococcus aureus and Staphylococcal Enterotoxins. In: COMPENDIUM of methods for the microbiological examination of foods. $4^{\text {th }}$ ed. Washington: American Public Health Association (APHA), 2001. p. 387-403

13 LISITA, M.O. Evolução da população bacteriana na linha de produção do queijo minas frescal em uma indústria de laticínios. Piracicaba, 2005. 61 f. Dissertação (Mestrado em Ciências) - Curso de Pós-Graduação em Ciências, Escola de Agricultura Luiz de Queirós, Universidade de São Paulo, Piracicaba, 2005.

14 LOGUERCIO, A.P.; ALEIXO, J. A.G. Microbiologia de queijo tipo minas frescal produzido artesanalmente. Ciência Rural, Santa Maria, v.31, n.6, p. 1063-1067, 2001.

15 MELO, A.C.M. de; ALVES, L.M.C.; COSTA, F.N. Avaliação da qualidade microbiológica do queijo tipo minas padrão comercializado na cidade de São Luis, MA. Arq. Inst. Biol., São Paulo, v.76, n.4, p.547-551, 2009.

16 PERRY, K.S.P. Queijos: aspectos químicos, bioquímicos e microbiológicos. Química Nova, São Paulo, v.27, n. 2, p.293$300,2004$.

17 SALOTTI, B.M.; CARVALHO, A.C.F.B.; AMARAL, L.A.; VIDAL-MARTINS, A.M.C.; CORTEZ, A.L. Qualidade microbiológica do queijo minas frescal comercializado no município de Jaboticabal, SP, Brasil. Arquivos do Instituto Biológico, São Paulo, v.73, n.2, p.171-175, 2006.

18 SILVA, W.P.; GANDRA, E.A. Estafilococos coagulase positiva: patógenos de importância em alimentos. Higiene Alimentar, São Paulo, v. 18, n. 122, p. 32-39, 2004.

\section{AGRADECIMENTOS}

Ao Conselho Nacional de Desenvolvimento Científico e Tecnológico, processo 478100/04-3, pelo suporte financeiro. 